\title{
A propósito del innatismo agustiniano en la escuela agustiniana
}

\section{A MODO DE INTRODUCCION}

Es sorprendente la coincidencia, en el planteamiento del problema del conocimiento, de tres grandes filósofos: Platón, San Agustín y Kant. En ellos la visión del problema es común, las soluciones son análogas, los resultados, es verdad, totalmente diversos. Por esto mismo, descartados los resultados idealistas platónico y kantiano, pero apoyándonos en lo que las tres soluciones tienen de común, podría pensarse en la verdad objetiva, como muy "viable y quizás única" 1 , de la solución agustiniana, y en que valga la pena recordarla para que se vaya afianzando en el ambiente intelectual. Siempre será bueno insistir en lo que pudiera ser su fijación definitiva, ya que no puede pensarse hoy en día en una identificación de las iluminaciones agustiniana y aristotélico-tomista, $y$, por otra parte, teniendo en cuenta que la solución agustiniana evita los inconvenientes de las soluciones platónica y kantiana.

Siempre serían buena excusa, para una reconsideración de la postura agustiniana, palabras como las que ha escrito Hessen a este propósito: "Que la noética agustiniana sea, por tanto, superior a una noética tomista basada en Aristóteles, y que ésta necesite ser completada por la agustiniana es opinión que ha comenzado a abrirse camino entre todos aquellos pensadores católicos que se enfrentan a la filosofía moderna con un espíritu abierto y tratan de sacar partido de ella" 2 . De hecho, ciertos pensadores contemporáneos, qưizá sin darse cuenta de ello, están pensando con una mente agustiniana. Nos place citar en concreto a Lersch cuando nos habla de ciertas "imágenes preconscientes y no objetivadas en representación", que "actúan como esquemas anticipantes a priori", designadas "como protofantasía": contenido cognoscitivo "preconsciente (que) sólo se materializa al contacto con la realidad", "condición esencial para la percepción de la forma, actuante en los animales pero que no puede entrar en juego sin el concurso de

1 J. Morán, "Hacia una comprensión de la "Memoria Dei" según San Agus tín": Augustiniana 10 (1960) 185-234.

2 J. Hessen, La filosofía de San Agustín, Cartagena 1962, 94-95, 
la experiencia, habida cuenta, sin embargo, de que las experiencias son imposibles sin la colaboración de aquélla". Según este autor la protofantasía vendría a representar una síntesis entre el idealismo y el sensualismo, y a ocupar una posición intermedia; sus palabras son terminantes, y cuando se ha leído un poco a Agustín, parece percibirse en ellas un cierto eco de su doctrina. Así, por ejemplo, cuando escribe el mismo Lersch: "Con la expresión protofantasía se supone que las imágenes de lo que se descubre en la percepción como unidad de forma y totalidad significativa se hallan preformadas en el psiquismo de un modo preconsciente y no representativo y son puestas de relieve en la percepción del mundo intermedio de los órganos de los sentidos" ${ }^{3}$. Según esto cabría pensar en una analogía entre el conocimiento intelectual humano y el conocimiento sensitivo animal. ¿Por qué sentido habrían entrado en el animal una serie de "relaciones" de las que hace uso y que no son objeto propio de ningún sentido concreto? Pero sobre todo quisiéramos citar aquí un movimiento italiano recientemente iniciado en favor de una purificación del tomismo aristotélico a base de una interpretación auténtica de Santo Tomás. En el primer número de 1963, de la revista "Filosofía e Vita" 4 , se nos recuerda a un autor contemporáneo que, al poner en relación el "lumen intellectus agentis" de Santo Tomás con el "essere ideale oggettivo" de Rosmini, habría hecho más o menos la siguiente afirmación: un tomismo aristotelizante no correspondería a la mente genuina de Santo Tomás; en cambio, un tomismo platonizante sería más adecuado como expresión de la mente del Angélico. Según Muzio, el autor en cuestión, la iluminación vendría concebida como "una certa efficienza per mezzo della quale la permanente intelligibilitá delle cose diviene formalmente in atto nell'intelletto". Y la razón que da se refiere siempre a lo mismo: "La riserva fondamentale del Muzio contro tale tomismo é quella stessa di Kant e poi ancora di Rosmini, contro ogni forma di empirismo che non puó fondamentare la trascendentalitá" 5 . Posteriormente la labor de Muzio y de sus colaboradores se ha intensificado. Sinceramente creemos que el tomismo aristotélico está siendo sometido a verdadera prueba por parte de los Quaderni "Sodalitas Thomistica". Téngase en cuenta que no se pretende en ellos, ni mucho menos, desplazar a Santo Tomás del lugar que le corresponde en el campo filośfico escolástico; todo lo contrario: "Noi pensiamo che l'autentico tomismo essenziale possa costituire l'asse fondamentale di un sistema di ispirazione cristiana... "Le repetute affermazioni di Paolo VI -che San Tommaso deve essere il Maestro principale ma non esclusivo, non unico - sono una implicita ma evidente raccomandazione, un autorevole invito a mettersi d'accordo su un tomismo essenziale 'che possa accogliere nelle sue linee

3 Ph. LeRsCH, La estructura de la personalidad II, Barcelona 1959, 396. Véanse también las pp. 372, 601, 602 y 604 .

4 E, NICoLETTI, "L'essere ideale oggettivo": Filosofia e Vita 4 (1963) 40-48. 
fondamentali le varie prospettive o accentuazioni delle altre correnti cristiane... En una serie de Quaderni ${ }^{5}$ Muzio, una vez presentado Santo Tomás como "la piú grande figura del pensiero" al lado de Platón, Aristóteles y San Agustín, que son los únicos que "prima di lui possono vantare una trattazione filosofica vasta - profonda come la sua", se plantea valientemente la cuestión del tomismo, o mejor, de un tomismo que pierde terreno precisamente porque no corresponde al pensamiento de Santo Tomás; Muñoz Alonso ha dicho que el Doctor Angélico sería "uno de los pensadores más inéditos de la historia de la filosofía, el eterno olvidado entre las páginas de tanto manual tomista" " ${ }^{6}$. En una palabra, la posición de Muzio se mantiene en línea recta en esta afirmación: una cosa es que Santo Tomás sea el maestro principal (no el único) de las escuelas católicas, como quiere la Iglesia, y otra muy distinta es que deba serlo según una interpretación de tipo demasiado aristotélico y no según la interpretación platónico-agustiniana de la que le hacen enemigo irreconciliable los partidarios de un aristotelismo que al mismo Santo Tomás resultaría extraño.

En fin, los entusiastas de este movimiento de renovación se han empeñado en una batalla que se propone "togliere la patina aristotelica che nasconde il vero volto di S. Tommaso ?.

\section{LINEAS GENERALISIMAS DE LA NOETICA AGUSTINIANA}

Para quienes no están todavía familiarizados con la tesis agustiniana sobre el conocimiento recordamos aquí los puntos más fundamentales.

El concepto de "memoria Dei", con que se ha venido denominando esta doctrina, es de cuño, si se quiere, reciente como expresión que ya va circulando en el ambiente intelectual para designar en psicología la iluminación del alma ${ }^{8}$.

Conviene ante todo señalar la situación ontológica del hombre agustiniano, colocado entre dos órdenes extremos: espíritu y materia, participando de entram-

5 Sodalitas Thomistica lleva ya publicados diez Quaderni muv tentadores a este propósito; he aquí los títulos: 1) Il divino nella natura e nella intelligen$z a$ (160 textos latinos con introducción y notas de P. Barale y G. Muzio; 2) La creazione dell'anima umana (60 textos latinos de Santo Tomás con introducción y notas de G. Muzio); 3) Immanenza del divino e trascendenza di Dio (Textos de Santo Tomás con introducción. notas y discusión de G. Muzio); 4) Torniamo a San Tommaso. Interpretazioni neoscolastiche e interpretazione rosminiana, por P. Barale y G. Muzio; 5) Rosmini e la Scolastica (Prólogo y Apéndice crítico de G. Muzio); 6-7) Il senso ortodosso e tomistico delle auaranta proposizioni rosminiane. por G. Muzio; 8) Della cognizione secondo S. Tommaso è Aristotele (Prólogo y notas de G. Muzio); 10) Il principio della conoscenza. Il Maestro interiore, de San Buenaventura (Traduzione e commento di G. Muzio).

6 MuÑoz Alonso, "Actualidad de Santo Tomás": ABC, 9-V-1966.

7 F. DeCHet, Giornale di Metafisica, Maggio-Giugno 1963.

8 L. Cilleruelo, "La "Memoria Dei" según Saṇ Agustín”: Augustinus Magister, I, París 1954, 499-509. 
bos a la vez, poniéndose en contacto con el primero mediante el entendimiento, y con el segundo a través de los sentidos y de la razón. Así es como distinguiremos con toda claridad dos fuentes específicas de contenidos de conocimiento: los sentidos por un lado y la memoria Dei por otro.

\section{a) LOS SENTIDOS,}

Son abundantes los textos a propósito de la primera fuente, origen de ciertos contenidos ideales que sólo se obtendrán a través de los sentidos. Así, por ejemplo, nos hablará de las fantasías corporales causadas por los sentidos; de los sonidos de los nombres a partir de las imágenes impresas por los sentidos del cuerpo. Si recorremos las puertas abiertas en nuestra carne - siempre los sentidos- podremos escuchar continuamente su mensaje; los ojos no cesan de decirnos: si se trata de algo colorado, nosotros lo hemos anunciado; si de sonidos, los oídos reclaman el haber hecho la indicación; nada sabe el sentido del gusto si de sabores no se trata, al paso que el tacto ignora lo ajeno a lo que se presente como mole corporal. El alma sufre una llaga a través de los sentidos, teniendo como resultado una de las tres clases de imágenes de que podemos hacer mención en el contenido de nuestro conocimiento; explícitamente nos advierte que los conocimientos corporales son recogidos por la mente mediante el instrumento corporal ${ }^{9}$.

A propósito de esta primera fuente de conocimiento, señalamos la concepción peculiar agustiniana acerca de la sensación como algo que es formalmente del alma sola y no del coniunctum. En el De Trinitate, en el $D e$ quantitate animae y en el De musica ${ }^{10}$ se encuentra el pensamiento agustiniano acerca del proceso de la sensación. Es clásica la frase del "sentire non est corporis, sed animae per corpus" ${ }^{11}$, reservando para la impresión orgánica el papel de mera instrumentalidad. Hay que reconocer ciertamente el punto oscuro que presenta el paso obligado de lo orgánico a lo espiritual que tanto ha hecho sudar al tomismo tradicional. Bien pudiera ser que hubiera de resolverse no insistiendo tanto en la necesidad de una causalidad de lo material sobre lo espiritual, sino más bien haciendo hincapié en el hecho de la unión sustancial entre el alma y el cuerpo y en el dominio y señorío ${ }^{12}$ del espíritu sobre la materia. Parecería muy natural

9 De Trinit. IX, 6 y 12, n. 18, PL. 42, 966; Confess. X, 14, 22, PL. 32, 789 ; Ibid. X, 10, 17, PL. 32, 786; Epist. VII, n. 3, PL. 33, 69; De Trinit. IX, 3, 3, PL. 42, 693; Epist. VII, n. 4, PL. 33, 69.

10 U. Alvarez, "El conocimiento sensible y el problema de la abstracción en San Agustín": La Ciudad de Dios 154 (1961) 5-22.

11 De Gen. ad litt. III, 5, 7; PL. 34, 282.

12 "Perabsurdum est fabricatori corpori quoquo modo animam subdere. Numquam enim anima est corpore deterior... Esset autem si aliquos in ea numeros corpus operaretur. Non ergo cum addimus fiunt in anima numeri ab 
que fuera el espíritu (teniendo tan presente, a causa de la unión sustancial, al cuerpo), sin imaginar un influjo de lo material sobre lo espiritual, el que se diese cuenta de lo que sucede en un algo que le está tan íntimamente unido, que él gobierna y en el que, en un momento determinado, ha sufrido un impacto o impresión por parte de un objeto sensible ${ }^{13}$.

\section{b) Exis'tencia de la "MEMORIA Dei".}

La segunda fuente de contenidos ideales del conocimiento humano es lo que en San Agustín se ha llamado "memoria Dei". Esta memoria Dei, en el hombre, por supuesto, no ha de ser identificada con el entendimiento, sino más bien con un apriori de inteligibilidad objetiva nocional, un verdadero contenido intelectual habitual, aunque no formulado, no expresado en ideas; lleva el calificativo de "Dei" porque es una verdadera participación de la suprema verdad por la que el entendimiento humano es iluminado.

La constatación de la existencia de esta "memoria Dei" en San Agustín es algo que se verifica en la experiencia interna, en hechos psicológicos que se traducen en tendencias, búsquedas, ansias de algo trascendental que sobrepasa la capacidad de los sentido, y que, por consiguiente, exige una especie de objeto distinto del de los sentidos. Así, por ejemplo, tenemos en primer lugar la tendencia a la felicidad, que es un amar la felicidad, una búsqueda de la felicidad. Ahora bien, no se comprende esta tendencia, búsqueda o amor sin un conocimiento inicial de la misma, según aquello de que "nada se desea si antes no se conoce" ${ }^{14}$. Esta tendencia a la felicidad está íntimamente unida al conocimiento del bien que se requiere como noción previamente impresa ${ }^{15}$. Tenemos también la tendencia a la verdad, que supone asimismo un conocimiento preconsciente de la misma ${ }^{16}$. En ambos casos un sutil análisis psicológico instrospectivo lleva a Agustín a la afirmación de estos contenidos apriorísticos. En todo nuestro conocimiento tenemos un saber y un creer. El creer es siempre posterior a lo que hemos oído; el saber, en cambio, es anterior. A poco que reflexionemos nos damos

iis quod in sonis cognoscimus" (De musica VI, 5, 9, PL. 32, 1.167). "Eamdem eiusdem (corporis) imaginem non corpus in spiritum, sed ipse spiritus in seipso facit celeritate mirabili, quae ineffabiliter longe est a corporis tarditate" (De Gen. ad litt. XII, 16, 33, PL. 34, 467.

13 De musica VI, 5, 9, PL. 32. 1.167.

14 De Trinit. XIII, 5, 8, PL. 42, 1.020; De lib. arb. II, 9, 26, PL. 32, 1.255. 15 De Trinit. VIII, 3, 4, PL. 42, 949.

16 "Nec amarent nisi esset aliqua notitia eius in memoria eorum" (Confess. $\mathrm{X}, 23,33$, PL. 32, 754). "Sicut... mentibus nostris impressa est notio beatitatis... ita etiam priusquam sapientes simus, sapientiae notionem habemus impressam, per quam unusquisque nostrum si interrogetur velitne esse sapiens, sine ulla caligine dubitationis se velle respondet" (De lib. arb. II, 9, 26, PL. 32, 1.255; Ibid. II, 12, 34, PL. 32, 1.259; Ibid. III, 5, 13, PL. 32, 1.277; De Trinit. XII, 3, 3, PL. 42, 999). 
cuenta de que aquello que se nos explica era, en el segundo caso, algo experimentado por nosotros, como algo ya sabido, y que únicamente no habíamos llegado a formular; algo parecido a lo que sucede a veces cuando, habiendo tenido ya la idea de una cosa, no se encuentra la expresión adecuada de la misma, pero, apenas insinuada por otro, decimos inmediatamente: eso es precisamente lo que quiero decir. Evidentemente se trata de todos aquellos casos en que los conocimientos no tienen realización en el orden sensible ${ }^{17}$. Llama la atención de Agustín la ley de la unidad, inseparable del ser, ya que el ser y la unidad se identifican, siendo inútil, por otra parte, pretender encontrarla en la multiplicidad característica de todo lo que es objeto de los sentidos: "si fueseis la misma unidad, no setiais cuerpo" ${ }^{18}$. Otras nociones apriorísticas son la de semejanza e igualdad; ¿cómo se podría medir sin poseer antes un patrón de medida? La medida es lo que debe ser asi y no puede ser de otra manera, al paso que los objetos de los sentidos son así y podrían ser de otra manera. Ahora bien, esta "igualdad suma que no veo con los ojos del cuerpo sino de la mente" 19 y la "regla de la semejanza" se encuentran impresas ${ }^{20}$. Finalmente, sobre todos estos ejemplos campea el caso de la ley natural, que comúnmente se considera como patrimonio no aprendido sino como "escrito en la naturaleza racional". Pero ¿qué quedaría de verdad en dicha afirmación si toda esa "expressio legis aeternae" en el hombre se reduce a una capacidad o potencialidad para conocer las verdades del orden moral? En ese sentido, ya que el más y el menos no cambia la especie, cualquier conocimiento, independientemente de la rapidez con que pueda ser obtenido, pertenecería al contenido "impreso" de la ley natural. Sólo con una teoría como la de la "memoria Dei" tiene sentido hablar de "expressio" de la ley eterna en la criatura racional. Finalmente no se han de echar en olvido las leyes de la estética y de las matemáticas, las cuales "ni son coloradas, ni sonoras, ni olorosas, ni sápidas, ni caen bajo el sentido del tacto" 21 .

\section{c) NATURALEZA DE LO INNATO NOCIONAL.}

Tratando de la naturaleza de esta "memoria Dei" hay que evitar el pensar en las ideas platónicas, $y$, por consiguiente, que nuestro conocimiento sea un mero "recordar". El contenido de la "memoria Dei" es un contenido nocional, algo informe como idea, pero capaz de ser formado, expresado; es un quiddam

17 De Trinit. IX, 6, 9, PL. 42, 966; Confess. X, 10, 17, PL. 32, 786: "cum ea didici, non credidi alieno cordi, sed in meo recognovi et vera esse approbavi et commendavi ei...".

18 De vera relig. XXIII, 60, PL. 34, 149: "cuius perceptio per corporis sensus non fit"; (De lib. arb. II, 8, 22, PL. 32, 1.252).

19 De vera relig. XXXI, 57, PL. 34, 147.

20 De Trinit. VIII, 5, 8, PL. 42, 953.

21 Confess. X, 12, 19, PL. 32, 797. 
mentis nostrae, illud mentis nostrae 22 ; es de "carácter metafísico..., un praesto esse, cuya vivencia intelectual sería la noción" ${ }^{23}$; hace relación a lo que debe ser, viniendo a ser como una imagen intelectual de las razones eternas existentes en el Verbo. De ahí la expresión "ver en las razones eternas" que nada tiene que ver con un ontologismo.

Ahora bien, ¿podríamos contentarnos con interpretar estas nociones agustinianas como simples reglas para formar juicios? Así piensa Gilson, cuyas son las siguientes palabras: "Nous tenons seulement de lui que l'illumination nous donne des "notions" d'origine non empirique, dont tout le contenu se réduit pour nous aux jugements qui les expriment, il ne nous dit si ces "notions" intelligibles sont quelque chose en dehors des tègles ou jugements en qui elles s'explicitent; affirmer le role régulateur et formel de l'illumination augustinienne est donc se tenir sur un terrain sûr; c'est encore etre sur un terrain non moin sûr que refuser de voir dans cette illumination un substitut de l'abstraction, car meme a supposser qu'elle nous donne des "notions", elle ne nous donne; vouloir aller au delà et décider si l'illumination nous donne une "notion" distincte de règles ou principes de jugement que les noms de "justice", "sagesse" ou "charité" designent, c'est ce que l'on ne peut faire sans depasser les textes actuellement connu de nous, car Augustin ne nous disant rien sur ce que de telles notions pourraint être elles memes, il ne nous dit rien que nous autorise soit à les affirmer, soit à les nier..." 24. Sin embargo creemos poder afirmar todo lo contrario Es cierto que San Agustín a veces nos habla de "reglas o leyes eternas" según las cuales, aun los impíos, por ejemplo regulan su modo de pensar acerca de la moralidad humana, diciéndonos también dónde tiene su origen ${ }^{52}$. Pero recordemos: San Agustín enseña un innatismo nocional porque ciertos contenidos (ser, felicidad, unidad, justicia, etc.), no se encuentran por la vía empírica. Ahora bien, unas reglas, unas leyes sin contenido ¿qué regularían?, ¿ para qué servirían? O mejor, distingamos: cuando se trata de formar las ideas acerca de los objetos de los sentidos, cuando se trata de universalizar tales contenidos del orden sensible se podría pensar en unas ciertas reglas o especies de contenidos nocionales que no signifiquen a no ser con (las reglas, por ejemplo, de la semejanza, de la igualdad, etc.). Privadas, aun éstas, totalmente de contenido, más parecerían categorías kantianas que otra cosa. Pero hay algo más interesante contra esta interpretación del ilustre Gilson. Conviene recordar que San Agustín está preocupado precisamente por determinar la originación de contenidos conceptuales bien determinados (justicia, unidad, estética, ley natural, etc.), cuya existencia no encuentra

22 De Trinit. XV, 15, 25, PL. 42, 1.079).

23 J. MorÁn, "Hacia una comprensión de la "Memoria Dei" según San Agustín": Augustiniana 10 (1960) 211.

24 E. GILson, Introduction a l'etude de S. Agustin, París 1943, 124-125.

25 De Trinit. XIV, 15, 21, PL. 42, 1.052. 
realizada en el orden sensible y por lo mismo tiene que contemplarlos en las razones eternas, según lo ya explicado. Lo que pasa es que esa "belleza", "justicia", "ser" son también normas, reglas según las cuales, no ya conocemos la belleza, la justicia, etc., sino más bien juzgamos acerca de los objetos de los sentidos y sentenciamos cómo debieran ser, o cuánto les falta para asemejarse al ideal concreto que no encontramos por ninguna parte y que, sin embargo, nos bulle en nuestra interioridad. Podríamos establecer una analogía entre este estado de cosas y el del artífice que tiene en su mente un modelo preconcebido que ejecuta exteriormente, y que, una vez realizado, es juzgado a la luz del modelo al que quizá no acaba de adecuar ${ }^{26}$.

En conclusión. Tendríamos nociones específicas diversas y no sólo reglas en general; no ideas formadas sino algo así como gérmenes de ideas. Quien se extrañarse de esta expresión "gérmenes" piense a qué quedará reducida, en la psicología tradicional, una idea que en un momento tenemos y después ha dejado el lugar a otras, y que en un momento siguiente somos capaces de volver a representar en el entendimiento. Tales nociones son inconscientes hasta que el entendimiento tenga ocasión de formularlas en ideas: "aprensiones inconscientes del objeto de las que se está informado sin percatarse de ello" 27. Así entendidas, se puede hablar de un cierto "recordar", no algo ya conocido en un estado preexistencial y existente en el "lugar de los inteligibles" platónico, sino partiendo de aquella luz con la cual, aun estando de ella apartados, estamos de hecho en contacto ${ }^{28}$.

\section{d) LA FORMACIÓN DE LAS IDEAS.}

Que no haya lugar a una abstracción efectiva en San Agustín, parece claro. Nos referimos a una abstracción que desmaterialice al fantasma. En este sentido tiene razón Gilson cuando dice: il n'y a pas chez Augustin de probleme de

26 De vera relig. XXXI, 58, PL. 34, 148; Epist., 162, 3, PL. 33, 705; De Trinit. XII, 2,2 , PL. 42, 999.

27 J. Morán, "Hacia una comprensión de la "Memoria Dei" según San Agustín": Augustiniana 10 (1960) 205.

28 De Trinit. XIV, 15, 21, PL. 42, 1.052. Contra la interpretación de Gilson es necesario recordar el De legibus de Cicerón, a quien tan bien conocía Agustín. En dicho tratado Cicerón habla de la ley que es algo innato en la naturaleza, antes nacida que escrita, de un contenido objetivo no suficientemente expresado, inteligencia incoada, razón recta de lo preceptivo y prohibitivo. Pues bien, aquí se trata de ley en sentido ético, por consiguiente con contenido bien determinado. Sin duda, Agustín hace extensivo el nombre "ley" a las nociones innatas que son como modelo según el cual se juzga; aparte de que siempre nos indica el objeto sobre el que recae la función reguladora: felicidad, justicia, belleza, ser, etc. (V. Traité de Lois, texte établi et traduit par Georges de Plival, Societé d'edition "Les belles lettres", París 1959, lib., I, 6, 18, 19, 22; Ibid. 8, 25; Ibid. 9, 26, 27; Ibid. 10, 30; Ibid. 11, 33). 
liunsetzung $d u$ sensible en intelligible ${ }^{29}$. Cierto lo que dice también este autor acerca de la preocupación principal de San Agustín: "le point de vue d'Augustin est moins celui de la formation du concept que celui de la connaissance de la verité". Otra cosa es que haya una ausencia total de elementos que nos permitan señalar en líneas generales el proceso de la formación de los conceptos. En resumen, el innato nocional proporciona: 1) ciertos contenidos intelectuales que no se encuentran en los sentidos; éstos se desarrollarán como reacción intelectual del sujeto que, en su parte material, ha experimentado un impacto sensible (no se olvide la unión sustancial entre el alma y el cuerpo); precisamente el contenido ideal se desarrollará como norma según la cual juzgará el entendimiento ese contenido concreto y singular recibido por los sentidos; 2) una segunda clase de contenidos ideales que nos servirían para universalizar los contenidos que son objeto formal de los sentidos, y también para construir los conceptos ideales generales: predicables y predicamentales en sí mismos considerados, es decir, prescindiendo de un contenido determinado; por ejemplo, género, especie, sustancia, relación, etc.; 3) elementos del orden sensible, los objetos de los sentidos.

Así, pues, la formación de lo conceptual, que no es del orden sensible, se verificaría, por ejemplo, de esta manera: un golpe recibido será captado por los sentidos como simple choque y nada más, es decir, independientemente de la justicia o injusticia con que haya sido dado. Expenimentada la sensación, el entendimiento será el que reaccione, a base de lo innato nocional, lo que ese golpe puede tener de razón suficiente: justicia o injusticia; de posibilidad de participación por muchos individuos: diversos predicables. La mente, usando el símil agustiniano ${ }^{30}$, cosiendo y recosiendo el paño ofrecido por los objetos de los sentidos con las modalidades nocionales del alma al apreciarlos: comienzo, permanencia, anterioridad, dependencia, etc., constituiría los universales. El hilo, para dar unidad a ese conjunto, lo proporcionarían ciertas nociones innatas: semejanza, unidad, simetría, etc. El resultado, los universales directos formales y los universales reflejos.

N. B.-Una cosa es absolutamente cierta en el pensamiento agustiniano: la existencia del innatismo nocional que abarca todo lo que no es objeto formal de los sentidos; ni menos cierta es la dificultad del paso de la impresión orgánica a la "llaga" en el alma en la sensación; pero no se ve inconveniente ninguno en admitir un principio de solución de esta dificultad a base, como queda dicho antes, del dominio y señorío del espíritu sobre la materia, que la capacita para "darse cuenta" de lo que sucede en algo que le está sustancialmente unido. $Y$ no se

29 E. Gilson, o. c., 115-116.

30 "...sumendo et quasi assuendo componere..." (De Trinit. XI, 8, 14, PL. $42,995)$. 
olvide lo que la ciencia nos dice hoy acerca de la imagen material, perfectamente grabada y guardada en la parte orgánica, que explica lo que de material puede asignarse a la sensación, quedando en exclusiva para el espíritu (tratándose del hombre) la parte formal, el "non latere" de San Agustín.

\section{VICISITUDES POSTERIORES DEL PENSAMIENTO AGUSTINIANO}

\section{I.-FUERA DE LA ESCUEla históRICA AgUSTINIANA.}

Aristóteles y San Agustín fueron los inspiradores de la superación del idealismo platónico al aceptar el conocimiento objetivo del orden sensible como parte integrante del conocimiento humano ${ }^{31}$. Históricamente, y de ellos dependiendo, son dos las corrientes de dicha superación: la de Agustín, que domina en general el pensamiento de la filosofía occidental a él posterior y que cristaliza en la escuela franciscana ${ }^{32}$, y la de Aristóteles que, principalmente a través de la filosofía árabe, va insinuándose en el pensamiento de la naciente escolástica. El P. Izzalini nos presenta una como línea histórica de la influencia aristotélica en los predecesores escolásticos de Santo Tomás: el agustinismo avicennizante de Domingo Gundisalvi ${ }^{33}$ sería el principio del movimiento aristotélico. Van apareciendo sucesivamente el babitus principiorum de Guillermo de Augverne ${ }^{34}$; el intellectus, que no está ad purum defaecatus, de Roberto de Grosseteste ${ }^{35}$; el entendimiento agente, de la obra "De intelligentiis", de autor desconocido ${ }^{36}$, de carácter, sin embargo, iluminístico interno, sin la abstracción del sensible; el entendimiento agente-dios, de Ruggero Baccone ${ }^{37}$. A medida que este entendimiento agente va abriéndose paso, se le va considerando cada vez más como algo del alma, aunque no distinto del posible, como en Alejandro de Hales ${ }^{38}$. Se piensa también ya en una extracción de la especie inteligible, con Juan de

31 E. Portalie, "San Agustín": DTC. I, 2.501 ss.; J. Hessen, "Augustinismus und Aristotelismus in Mittelalter": Franziskanischen Studien 7 (1920) 2.

32 Hablando de la postura agustiniana de San Buenaventura nos dice el P. Pelayo de Zamayón: "La doctrina del Santo es personal y completa; si no la explica con más amplitud fue porque en su tiempo no era preciso, admitiéndose el agustinismo como doctrina demostrada", en Hacia Dios (Cinco lecciones acerca del Itinerario, de San Buenaventura, texto original y traducción ${ }_{n}$ Roma 1940).

33. L. D'IzzaLINI, Il principio intellettivo della ragione umana nelle opere di S. Tommaso d'Aquino, Roma 1943, 1-54.
34 Ibid. 32.
35 Ibid. 35.
36 Ibid. 35.
37 Ibid. 36.
38 Ibid. 37. 
Rupella ${ }^{39}$. Este es el panorama con que se encuentra Santo Tomás: un agustinismo operante en la doctrina corriente y un aristotelismo peligroso que inexorablemente se hacía presente. San Alberto, finalmente, introduce los dos entendimientos (agente y posible), con una interpretación de Aristóteles que hoy resulta ya muy problemática, aunque no puede librarse del todo de la iluminación agustiniana.

¿Y Santo Tomás? Todos sabemos que el Angélico cristianizó -por decirlo con una palabra ya vulgar - al Estagirita. Pero no se trata de esto. Lo que hoy se pone sobre el tapete es si el verdadero Santo Tomás es el Santo Tomás aristotélico que se encuentra en línea divergente con la doctrina agustiniana o que, a lo más, concuerda con ella a base de interpretarla en un sentido aristotélicotomista. Porque no es Santo Tomás el atacado, el puesto en entredicho, sino un tomismo aristotélico que ha pretendido ser el intérprete genuino y auténtico del Doctor Angélico ${ }^{40}$. Han nacido una serie de interpretaciones del tomismo que intentan señalarnos, cada uno a su manera, el pensamiento esencial del Santo. Volvemos a citar a Muñoz Alonso que nos dice que "tampoco es exacto el pretendido caráoter aristotélico del pensamiento tomista: vistió Tomás con palabras aristotélicas realidades muy distintas de las que al gran pensador griego se le ofrecieron" ${ }^{41}$. De ahí la exclamación de Muzio: ...ci sono molti tomismi... Quale è l'autentico? Domenicani o Gesuiti? Báñez o Molina? Lovanio o Milano? "Aquinas" o "Filosofia e Vita" 42. De aquí también el grito de alarma lanzado de diversas partes: "Aquinas", Gilson, De Finance, S. J., Vansteenkiste, O. P., Cornelio Fabro, etc., el último de los cuales llegó hasta decir que los 80 años de la Aeterni Patris, "si no terminan en un funeral del tomismo, pueden presentarse con un balance muy preocupante por culpa de los que se hacen pasar por sucesores de Santo Tomás". Y conste que se trata de divergencias dentro del neotomismo aristotélico, porque un tomismo platónico-agustiniano o un tomismo rosminiano ya quedaría al margen del aristotelismo-tomista ${ }^{43}$. Como se ve, muchos comparten el pensamiento de que hay que volver a un Santo Tomás auténtico a quien sería necesario concordar con San Agustín, San Buenaventura y Rosmini. "La crisi

39 Ibid. 38.

40 "Demasiado se ha insistido, por parte de algunas corrientes tomistas $y$ neotomistas, sobre el aristotelismo de Santo Tomás... Esto ha perjudicado al Santo Doctor, ha acabado por esterilizarlo, hacerlo extraño a la problemática del mundo moderno, inoperante en el desarrollo del pensamiento del Renacimiento en adelante... Es necesario reconquistarlo en la originalidad de su pensamiento, en su aristotelismo que es diverso del de Aristóteles. Santo Tomás, entendido así, no se encuentra sobre una línea divergente de la de San Agustín, sino que es desarrollo de ella...". (M. F. ScIACCA, Historia de la Filosofía, Barcelona 1958, 262-243).

41 A. Muñoz Alonso, A. B. C., 9-III-1966.

42 G. Muzio, Il Tomismo oggi, Roma 1966, 12.

43 C. FABRo, "S. Tommaso e la filosofia cristiana nel tempo presente": $F i$ losofia e Vita 1 (1969) 46, 47, 48. 
-nos dice Muzio- non è del tomismo ma del neotomismo aristotelico, più o meno opposto a Sant'Agostino, a S. Bonaventura e all'autentico Rosmini. Contro questo, e non contro il tomismo, si è messo lo spiritualismo cristiano; contro i manuali molto aristotelici e poco tomistici si ribellano anche i professori cattolici. E l'autentico spiritualismo cristiano... l'idealismo... lo supera confutandolo, affermando -con S. Agostino, S. Bonaventura, S. Tommaso e Rosmini- l'inmanenza della similitudine divina e la trascendeza di Dio. Il principio della "interiorità oggettiva" importa la presenza dell'essere, l'intuizione dell' "ipsum esse deductum a divino esse" ... ${ }^{44}$. Klaus Kremer nos habla también acerca de un apriorismo en la metafísica del conocimiento de Santo Tomás ${ }^{45}$.

De confirmarse esto, habría que afirmar que la teoría del conocimiento de Santo Tomás fue, en su tiempo, una verdadera genialidad para evitar el panté́smo averroista, justificar a Aristóteles e incorporarse a Agustín, huyendo al mismo tiempo del idealismo platónico; y la conclusión final creemos vendría a ser algo que ningún aristotélico-tomista podría perdonarnos si decimos que el Doctor Angélico pudiera ser considerado como un testigo más de la existencia de la "memoria Dei" en la tradición agustiniana medieval. Y de no ser así, la Suma Teológica se nos presentaría como una negación a corto plazo de las cuestiones De Veritate, arguyendo también como una especie de inscontancia e inseguridad de pensamiento en ese cambiar varias veces de opinión en el corto espacio de unos diez o doce años, lo cual no nos parece se avenga bien con el indiscutible ingenio del Angel de las Escuelas.

\section{II.-Dentro DE LA ESCUEla AgUSTINIANA}

\section{EL. Beato Santiago de Viterbo ${ }^{46}$.}

El siglo XIII ${ }^{47}$, en el que tiene lugar la fundación que podríamos llamar oficial o jurídica en la Iglesia de la Orden de San Agustín, es precisamente

44 G. MUzio, o. c. 15 .

45 K. KREMER, "Der Apriorismus in der Erkenntnismetaphysik des Thomas von Aquin": Divus Thomas, Piacenza 1928, 50-82.

46. El P. D. Gutiérrez tituló su tesis doctoral: De B. J. Viterbiensis O. E. S. A. vita, operibus et doctrina theologica, Romae 1939. He aquí una brevísima nota biográfica de Santiago de Viterbo: Nace hacia el 1255; inrgesó en la Orden agustiniana en 1272; hacia 1275 es enviado a París, donde, cursados los estudios reglamentarios, obtiene el grado de Lector. En 1281 vuelve a Italia y ejerce varios cargos en su Provincia Romana. En 1286 está de nuevo en París; grado de bachiller en 1288 y Maestro in sacra pagina en 1293. Hasta 1299 es en París maestro actu regens. Vuelve a Italia el 1300 y es nombrado arzobispo de Benevento en 1302 ( 3 de septiembre), pasando en el mismo año a la sede de Nápoles donde muere santamente a últimos de 1307 o principios de 1308.

47 Véase la magnífica obra de F. van STEENBERGHEN, La philosophie au $X I I I^{\ominus}$ siecle, Louvain 1966. 
cuando una abundante literatura científica y filosófica de origen griego, judío y árabe invade el occidente intelectual. La visión cristiana del universo se va enfrentando con la visión naturalista de Aristóteles. Ya la dialéctica aristotélica, aplicada a la Teología, había levantado sus tempestades en el mundo religioso del siglo XII. Su influjo comienza a ser arrollador, y algunos, como David de Dinando, actúan tan peligrosamente, imbuídos por una mentalidad aristotélica, que dan lugar a una serie de prohibiciones del Estagirita como medida de prudencia y de defensa contra sus doctrinas sospechosas. Y así en 1210 y 1215 se ponen en entredicho los Libri de naiurali pbilosopbia y la Metaphysica de Aristóteles, y los Commenta y Summae de sus discípulos. En fechas posteriores $(1231,1245,1263)$ hasta la gran condenación del peripatetismo en 1270, a la par de proscripciones y reservas, se va viendo la necesidad de revisar las obras del filósofo y también se van tomando posiciones encontradas; la escuela franciscana por un lado, la dominicana, que se va identificando siempre más con el tomismo, por otro. En la escuela histórica agustiniana, que reconoce como su primer representante a Egidio Romano, se suceden una serie de agustinos que no podrían ser encuadrados totalmente en ninguna de esas dos posturas sino que más bien se mueven con una cierta libertad reconociendo los méritos de cada una. El primero de estos agustinos es el sucesor de Egidio Romano en la cátedra de París, el Beato Santiago de Viterbo. Influído por el aristotelismo, como en general lo estaban más o menos los doctores de la época, debe ser situado, sin embargo, dentro de la corriente agustiniana medieval ${ }^{48}$.

\section{A) El INNATISMO EN LAS FACUltades COGNOSCITIVAS.}

En la teoría del conocimiento del tomismo-aristotélico se ha conservado como una especie de dogma la afirmación siguiente: el fantasma, resultado único como "actus coniuncti" del órgano-animado, es material; de ahí que sea necesaria, para cualquier conocimiento en el orden ideal, una desmaterialización del fantasma. Para ello consideraron necesario el entendimiento agente, encargado de llevar a cabo la operación. Santo Tomás nos indicará a este propósito una

48 Ocupándonos de su pensamiento filosófico en otra ocasión escribimos lo siguiente: Si, como es justo, se ha de enjuiciar la posición doctrinal de un autor del siglo XIII atendiendo no a aquellas tesis que constituían el patrimonio común de los escolásticos sino a aquellas otras características de cada grupo doctrinal, podemos afirmar que Santiago de Viterbo puede ser contado como representante de "un" agustinismo medieval en la escuela egidiana. En efecto, su pensamiento filosófico se nos presenta orientado completamente hacia doctrinas agustinianas...: primado de la voluntad sobre el entendimiento, ausencia de actividad propiamente causal del objeto en el acto representativo y la teoría de las razones seminales...; en el problema de las ideas se refleja la iluminación agusti. niana..." (F. CASAdo, "El pensamiento filosófico del Bto. Santiago de Viterbo"; La Ciudad de Dios 165 (1953) 498. 
"necessitas ponendi" 49. Pero esta desmaterialización del fantasma iba a ser la pesada cruz que dividiría a los tomistas a la hora de la explicación del hecho. Fuera del tomismo aristotélico se buscó una salida a base del innatismo nocional agustiniano; en concreto, en la escuela histórico-agustiniana hay una tradición constante de innatismo. Vaya por delante la observación de que, al relacionar a nuestros autores con San Agustín, no queremos subrayar una identidad de pensamiento en los detalles sino sólo en el hecho fundamental del innatismo nocional, de alguna manera en oposición a la "tabula rasa" tradicional".

En la solución del problema Santiago de Viterbo recurre al innatismo agustiniano aludiendo varias veces al texto en que San Agustín habla de conocer en las razones eternas ${ }^{50}$ lo que no se percibe por los sentidos. Pero de nuevo hacemos notar la diferencia: Santiago de Viterbo se sirve de la tesis agustiniana pero en razón de un fundamento diverso y con aplicación más extensa. Para San Agustín la razón del innatismo nocional es la serie de objetos que no son capaces de ser percibidos por los sentidos; en Santiago de Viterbo, en cambio, es la materialidad del fantasma. La línea general de su teoría del conocimiento sería la siguiente: el conocimiento es sensitivo e intelectual, cada uno con sus objetos peculiares y facultades adecuadas. Ahora bien, lo referente a la eterna cuestión de una transformación del objeto, desde que se percibe materialmente por los sentidos hasta que tenemos la idea del mismo, se resuelve a base de innatismo y de esta manera: Primero se tiene la impresión orgánica por acción del sensible sobre el órgano; en el "sentido" hay una "aptitud" o idoneidad capaz de formar una semejanza de la impresión orgánica; esto es posible gracias a la unión íntima existente entre la parte orgánica y el "sentido". La impresión orgánica sería el elemento material; el desarrollo de la idoneidad el elemento formal en la sensación. $Y$ no se habla sino de una sensación porque es tal la unión entre estos elementos, resultando el formal por la excitación del material, que práctica. mente es una sola cosa ${ }^{51}$. Esto es lo correspondiente a la parte sensitiva. Al dar

49 I, q. 79 , a. 3 c.

50 "...quod dixit Beatus Augustinus in pluribus locis: ait quod omnia cognoscimus in luce primae veritatis et in rationibus aeternis. Prima autem veritas Deus est; rationes vero aeternae sunt ideae rerum in Deo. In istis igitur dicitur animam omnia cognoscere, quia cognoscit per aptitudines ab his rationibus derivatas et sibi naturaliter inditas et semper in ea manentes..." (Ms. Ottob. Vat. lat. 198, fol. 93rb); "Deus enim impressit animae et indidit quasdam aptitudines et incompletas similitudines rerum cognoscibilium per quas movet se ad similitudines completas; et secundum hoc dicitur moveri a rebus: in quantum se movet ut assimiletur ipsis rebus; vel brevius dicamus, ut assimiletur illis aeternis rationibus a quibus et res ipsae derivatae sunt et aptitudines animae impraesae et inditae" (Ibid. fol 93v).

51 "Sensus itaque excitatus per immutationem organi corporei, per illas aptitudines movet se ad actus completos qui habent similitudinem cum immutationibus organorum, et inter imagines et immutationes organorum miscentur et coniunguntur formis et illis aptitudinibus reductis in actum completum ita quod est simul duplex actualitas, scil., immutatio ab obiecto et immutatio qua sensus 
esta interpretación, nuestro autor cree ofrecernos el pensamiento nada fácil, ni mucho menos, de San Agustín en el De Musica VI, XII super Gen. ad litt. y XI de Trin, $2{ }^{52}$. A continuación del conocimiento sensible se verifica el conocimiento intelectual, interpretado también a base del innatismo. Es decir, en el entendimiento nos encontramos con unas idoneidades innatas, y por cierto "secundum diversitatem intelligibilium"; estas idoneidades constituyen un verdadero innatismo nocional. Son las que capacitan al entendimiento para formar él mismo las ideas. Sin embargo, éstas no serán arbitrarias, pues, para que el entendimiento entre en funciones de entender o de formar las ideas, ha de ser "excitado" por el fantasma. Para esto no se necesita que el entendimiento purifique de alguna manera al fantasma, como se juzga necesario por los que defienden la existencia del entendimiento agente, sino que basta que la fantasía esté radicada en la misma sustancia del alma, de la que el entendimiento es también una facultad, y que se encuentre en acto ${ }^{53}$. Evidentemente las idoneidades no son ideas de tipo platónico ${ }^{54}$, ni tampoco las especies inteligibles del aristotelismotomista; sin embargo podríamos decir que tienen como una cierta analogía con éstas ya que son "secundum diversitatem intelligibilium" 55. Por eso más bien

movet se, quae proprie dicitur sensatio. Et immutatio quidem organi est magis materialis, immutatio vero sensus magis formalis. Licet autem sit duplex actualitas et immutatio, tamen propter coniunctionem sensus et organi, et immutatio organi redundat in sensum, et immutatio sensus concomitatur organo, propter quod sunt quidem una immutatio tum ratione coniunctionis tum ratione similitudinis" (Ibid. 93ra).

52 “...Augustinus qui in VI de Musica distinguit operationem sensus ab immutatione organi; in XI libro de Trinitate, c. 2 , impressionem quae fit in organo visus a re visibili visionem nominat, non distinguens immutationem organi ab operatione sensus quae est magis occulta" (Ibid.).

53 "Si itaque sensibilia vel ipsae immutationes organorum a sensibilibus movent sensum solum excitando, sensus autem excitatus movetur ex se, multo magis hoc dicendum est in intellectu, scil., quod phantasmata movent intellectum solum excitando, intellectus autem excitatus movet se ad actualem cognitionem et coniungitur actio vel operatio intellectus cum phantasmate, ita quod simul est immutatio intellectus, quae est intelligere, cum immutatione phantasiae quae est ipsum phantasma, ut nomine phantasmatis intelligatur non idolum quod imprimitur in organo phantasiae, sed ipsa operatio virtutis phantasticae. Ab hac ergo intellectus immutatur immediate, et inde est quod nihil sine phantasmate inteligit anima dum est corpori coniuncta. ...Ad hanc autem excitationem intellectus a phantasia non requiritur quod intellectus aliquam virtutem tribuat phantasmatibus, quamvis ignorabiliora sint intellectu, quia non oportet ad hoc quod aliquid moveat aliud per modum excitationis quod sit eo nobilius; sufficit autem quod ad ipsum habeat coniunctionem et ordinem et quod sit in actu secundum aliquid conveniens vel aliquam habitudinem habens ad id secundum quod natum est esse in actu quod excitari dicitur" (Ibid 93ra-rb).

54 "Sed haec opinio Platonis non est vera. Nom enim anima praeexistit antequam corpori uniatur et per consequens nullam bahet cognitionem" (Ms. Vat. lat. 982, fol. 31rb).

55 "Species in intellectus dupliciter sumitur: Uno modo pro naturali quadam aptitudine per quam se movet anima ad intelligendum actu: alio vero modo pro ipsa aptitudine per quam se movet anima ad intelligendum actu : alio vero modo pro ipsa cognitione actuali. Utraque species requiritur ad intelligen- 
consideramos estas idoneidades como innatismo nocional, como conocimiento incoativo de tipo metafísico ${ }^{56}$.

Nada, pues, de abstracción de especies ni, por consiguiente, de entendimiento agente. Las causas del conocimiento son: Dios que crea al alma con sus aptitudes; el alma que las produce, excitado el entendimiento por la fantasía y actuando a base de las idoneidades; los sensibles influyendo en las potencias sensitivas $y$, por medio de ellas, como queda dicho, en el entendimiento ${ }^{57}$.

\section{B) EL INNATISMO EN LA VOLUNTAD.}

Cuando hemos seguido investigando el pensamiento de este autor casi totalmente inédito, nos hemos encontrado con una cuestión quodlibetal en la que se vuelve a hacer alusión al innatismo, y precisamente como base para la solución del problema de la moción libre de la voluntad.

La cuestión que nos interesa lleva como título el siguiente: Utrum actus voluntatis in finem sit actus voluntatis vel intellectus. Hace el número 7 de las cuestiones quodlibetales y se encuentra en el primero de sus cuatro quodlibetos.

Este título, en realidad, no nos señala todo el contenido doctrinal de la cuestión; no va más allá de lo que podía ser un interrogante acerca del sujeto del acto con el que se tiende al fin; es decir, si es un acto del entendimiento o de la voluntad, en el sentido de que quizá el acto de la voluntad no se inicie en ella

dum et per utramque dicitur aliquid actu cognosci sed diversimode, nam per speciem quae est naturalis aptitudo dicitur aliquid cognosci tamquam per id quod est causa et principium cognitionis...; per speciem vero quae est ipsa cognitio actualis dicitur aliquid actu cognosci formaliter eo modo quo aliquid dicitur esse album per albedinem... Utraque species, videlicet tam naturalis aptitudo quam actualis cognitio, ab anima sicut a principio habet ortum sed diversimode: nam species quae est naturalis aptitudo immediate ab anima oritur eo modo quo proprietas oritur aut fluit a substantia sicut dicuntur potentiae oriri ob ipsa; species vero quae est actualis cognitio ab anima oritur mediante aptitudine praedicta" (Ms. Ottob. lat. 196, q. 12, fol. 95rb).

56 "... quoddam incompletum... dicitur aptitudo; etiam dici potest habitus non quidem acquisitus sed naturaliter inditus et... connaturalis" (Ibid. fol. 92vb); "Quaedam habitualis notitia quae semper inest animae" (Ibid. fol. 93va).

57 "Ad id quod additur quod secundum positionem praedictam scientia nostra non causatur a rebus, dicendum quod illud principaliter est causa scientiae in nobis quod principaliter animam movet ad cognoscendum. Anima autem movetur principaliter: a Deo quidem efficienter, qui ipsam producit a seipsa vero formaliter; a sensibus vero et sensibilibus movetur non principaliter sed per modum excitationis et inclinationis cuiusdam, ut dictum est, et ideo causa scientiae in nobis est Deus et ipsa anima; res sensibiles non principaliter sed aliquo modo" (Ibid. fol. 93rb); "Ab utroque ergo paritur notitia: et a cognoscente et a cognito; notitia enim actualis est similitudo cognoscentis et cogniti, et secundum hoc paritur ab utroque; tamen a cognito paritur solum ex hoc quod est eius similitudo; a cognoscente vero et quia est eius similitudo in quantum in cognoscente praeexistit. Notitia enim habitualis quaedam similitudo est notitiae actualis, et quia cognoscens movet se ad actualem cognitionem secundum illam habitualem quae est similitudo ipsius cogniti licet incomplete" (Ibid. fol. 93va). 
y por ella sino más bien como siendo inicialmente por parte de la voluntad una pasión causada por el entendimiento. Pero hay algo más; se toca también en esta cuestión la difinición misma de la libertad y el objeto de ésta.

La respuesta al interrogante del título viene dada en favor de la voluntad al exponer el modo según el cual la voluntad se mueve a sí misma.

\section{LA NOCIÓN DE LA VOLUNTAD:}

a) Por parte de Dios.-Partiendo de la libertad como característica de la libertad humana, no se puede admitir que la voluntad se encuentre en un estado de indiferencia pasiva sino más bien de indiferencia activa ${ }^{58}$; es decir, ha de estar en posesión del dominio de su acto ${ }^{591}$; debe ser principio de su acto. En una indiferencia pasiva la voluntad se movería necesariamente al recibir el influjo ajeno si éste fuese suficiente para sacarla de la pasividad o, de lo contrario, no habría actuación alguna a causa precisamente de esta pasividad. Pero, por otra parte, ¿Cómo puede entender este "moverse" de la voluntad, este "tener en su poder" el acto, este "ser principio de su acto" si se ha de tener en cuenta el famoso principio "todo lo que se mueve es movido por otro"? ${ }^{60}$.

El primer caso que se presenta es el de la voluntad respecto de su dependencia del motor universal: Dios. Pero no hay lugar para la predeterminación física. El movimiento de la voluntad se origina en la voluntad y procede de la voluntad. Si se habla de libertad tiene que salvarse el "se moveri" al acto de querer aunque de alguna manera sea influído por otro ${ }^{61}$. Pues bien, cuando se trata de la actividad de la voluntad respecto del Creador, Santiago de Viterbo hace una distinción entre la moción de la voluntad a lo que pudiéramos llamar el bien universal y lo que serían mociones particulares, determinadas, concretas respecto de los bienes particulares. La primera moción —al bien universal - es recibida de Dios; pero no se piense en una premoción física. Esta primera moción del Creador no es otra cosa que el "pondus" de la naturaleza, su inclinación natural al bien universal. Y esto basta para salvar la dependencia de la criatura y la independencia de Dios ${ }^{62}$.

58 "Voluntas movetur ex se ad volendum..., ita quod ad actum volendi non se habeat pure passive sed habet se active" (Quodl. I, q. 7, fol. 82rb; Ms. Ottob. Vat. lat. 196).

591 "Actus enim secundum quod habens motum est operatio libera quae est in potestate agentis" (Ibid.).

60 "Semper primum movens et primo motum sunt realiter diversa" (Fol.

61 "...illud quod liberum esse dicitur aut nullo modo movetur ab alio aut si movetur ab alio, movetur ex se" (Ibid. fol. 83ra).

62 "Duplex est motio: una quidem quae sequitur causam efficientem habentem formam completam, sicut calefactio sequitur calefacientem... Prima igitur motio semper est ab alio in aliud" (Ibid. fol, 84ra); "A Deo autem movetur per se efficienter" (Ibid. fol. 84vb). 
b) Por parte de sí misma.-Los movimientos de la voluntad respecto de los bienes particulares, o sea, las voliciones en relación con el fin concretamente apetecido o también respecto de los medios, son los que tienen que estar sometidos al poder de la voluntad si se quiere salvar la noción genuina de la libertad.

No se le oculta a nuestro autor que aun en este caso, es decir, cuando se trata de "moverse" en las voliciones concretas, si la voluntad está en potencia para tales voliciones, queda siempre en pie la cuestión del "quidquid movetur...", ya que en la medida en que está en potencia, está privada del acto que va a adquirir. Históricamente se han ofrecido soluciones diversas que Santiago de Viterbo conoce muy bien. Así, por ejemplo, no acepta la de los que acuden a la diferencia existente entre lo orgánico y lo espiritual. Análogamente a lo que sucede en el campo de la reflexión perfecta, posible en lo que es esencialmente espiritual, no admisible en lo orgánico, esos autores reservarían el valor del principio para lo material sin que tuviera que ser necesariamente aplicado a lo espiritual. Santiago de Viterbo contesta a esto muy acertadamente diciendo que el principio "quiquid movetur..." pertenece a lo más radical en el ser, a sus componentes de tipo trascendental: potencia-acto ${ }^{63}, \mathrm{y}$, por consiguiente, tiene un valor universal para todos los seres. Una segunda solución, la del acto "virtual", según la cual la voluntad se encontraría formalmente en potencia y virtualmente en acto, pudiendo, por lo mismo, pasar por sí misma de la potencia al acto, tampoco le satisface. Es cierto que una forma superior puede contener virtualmente las modalidades operativas de la forma inferior y producir sus efectos, pero no es éste el caso en el acto virtual respecto de la moción de la voluntad ${ }^{64}$. La razón de esto es que si el acto virtual es acto en la línea de la moción, lo es formalmente, pues tal acto moción, en cuanto tal, es indivisible. Así, pues, el acto virtual parece contradictorio considerado en lo más más radical de una potencialidad que tiene que pasar al acto. No viendo otra solución, Santiago de Viterbo recurre a un innatismo paralelo al innatismo intelectual de las "impresiones nocionales" de San Agustín, y evidentemente en él inspirado. Le da pie San Anselmo cuando escribe que el alma se mueve suis affectionibus. Es decir, en el alma, además de las potencias apetitivas, que son aptitudes generales para lo apetecible, habría en ellas unas aptitudes espe-

63 "Cum enim actus et potentia consequantur ens in quantum ens, distinctio eorum extendet se ad omnia entia sive corporea sive incorporea, ita quod sive sit aliquid incorporeum sive corporeum non potest simul et secundum idem esse in potentia et in actu, et per consequens etiam nec suipsius motivum" (Ibid. fol. $83 \mathrm{va})$.

64 "Sed et ista solutio non videtur esse nec conveniens nec sufficiens; nam esse actu formaliter et actu virtualiter facit quidem diversitatem in agentibus cuorum aliquod habet formam facti secundum eminentiorem rationem, et sic dicitur habere illam virtualiter, aliquod vero secundum eamdem rationem, et sic dicitur habere illam formaliter. Sed iste diversus modus actualitatis numquam potest efficere ut aliquid seipsum dicatur movere quia illud quod est actuale virtualiter numquam fit a se in potentia formaliter" (Ibid.). 
ciales, una especie de "virtudes", naturales y concretas en virtud de las cuales se apetecerían los bienes concretos y determinados. Esto es lo que pudiera llamarse, si cabe la expresión, virtualidad o "acto virtual", elemento innato que no es de tipo "noción" sino de tipo apetición. Esta idoneidad es algo que pertenece al predicamento cualidad en su segunda especie. Se denomina acto incompleto, no en el sentido de que al actuar la voluntad este acto incompleto se complete, se haga más perfecto en la misma línea, sino en el sentido de que capacita a la voluntad para originar un acto completo de volición distinto del que se denomina incompleto. Así se salva el que la voluntad esté en potencia para el acto completo y sin embargo pueda ser principio de su acto propio ${ }^{65}$. Así queda a salvo también el principio "quidquid movetur...".

En virtud de estas idoneidades de tipo apetición la voluntad que había sido movida "efficienter" por Dios, según queda dicho, se mueve a sí misma "formaliter" 66 .

c) Por parte del objeto $y$ del entendimiento.-En este apartado hay que hacer una distinción entre la moción de la voluntad en cuanto a la especificación y en cuanto al ejercicio. En cuanto a la especificación la voluntad es movida por la representación ideal del objeto, o por el objeto, que para el caso es igual ${ }^{67}$, pero no eficientemente como agente sino como fin al que se conforma. Así, pues, no se trata propiamente de una moción sino en un sentido metafórico ${ }^{68}$, como

65 "Quarto modo res omnes sunt in anima et anima est quodammodo omnes res, scil., per quamdam conformitaten et similitudinem... Verumtamen ista conformatio animae ad res dupliciter potest intelligi: uno modo in potentia, et sic anima conformatur rebus cum actu cognoscit aut appetit aliquid. Cum vero dicitur anima conformis rebus in potentia, quidam accipiunt potentiam pure passivam ad modum quo speculum dicitur potentia ad imagines et materia ad formam, quod quidem non videtur rationale: non enim secundum modum hunc videtur salvari quomodo actualis motio et informatio ipsius animae secundum quam dicitur conformis rebus vel cognoscendo vel appetendo dicatur actio et operatio animae et quomodo dicatur actus vitalis in agente manens. Sicut in quaestione de agente intellectu magis erit manifestum. Et ideo videtur esse dicendum quod cum anima dicitur esse potentia conformis rebus, huiusmodi autem potentia non est pure passiva sed est quaedam activa incompleta, et est inchoatio et exordium et praeparatio quaedam respectu actus ulterioris. Unde potest dici quaedam aptitudo et idoneitas ad completum actum; et est huiusmodi idoneitas animae connaturalis et naturaliter indita, ideoque semper in ipsa manens, sed quandoque imperfecta, quandoque vero perfecta per actus" (Ibid. fol. 83vb).

66 "Quantum enim ad exercitium actus movetur a se formaliter et a Deo efficienter" (Fol. 85ra).

67 "Intellectus movet voluntatem... uno modo ut est repraesentativa obiecti quod est extra, et hoc modo forma apprehensa movet voluntatem quantum ad determinationem actus sicut et ipsum obiectum extra, nam forma apprehensa, ut est similitudo obiecti et ipsum obiectum pro eodem accipiuntur" (Fol. 85ra-rb).

68 "Sed quomodo huiusmodi determinatio dicatur motio videtur esse dubium, et ideo sciendum quod movere quantum ad determinationem actus est movere metaphorice et non proprie quod potest sic intelligi : dicitur aliquid moveri metaphorice quia est terminus motus eo modo quo uno relativorum habet rationem termini respectu alterius, quod bene congruit obiectis potentiarum animae; 
término del acto de la voluntad especificándola. Tal es la moción por parte del objeto externo.

Por parte del entendimiento parece que su influjo sobre la voluntad, aparte del ya dicho de especificación a causa de la representación ideal del objeto, tendría algo que ver con la moción en cuanto al ejercicio. Desde luego, no se trata de un influjo directo del entendimiento sobre la voluntad -éste es propio de sólo Dios que mueve a la voluntad "efficienter" como queda explicado- sino de un influjo que se verifica indirectamente y de signo muy particular. Por radicar ambas facultades en la misma sustancia del alma, una vez actualizado el entendimiento por su objeto se tendría una especie de resonancia, redundancia o como excitación en la voluntad, originándose en ella una como inclinación al objeto, insuficiente, sin embargo, para sacarla de su potencialidad, pero útil para que la voluntad con las idoneidades propias pueda elegir, pueda actuar libremente 69 . Con esta especie de moción-inclinación se efectuaría la moción eficiente de la voluntad por parte del entendimiento sin que, sin embargo, haya lugar para un determinismo psicológico.

2. LA LIBERTAD DE LA VOLUNTAD.-Ya queda dicho arriba que, además de tratar esta cuestión $7 .^{a}$ del primer quodlibeto de la voluntad como sujeto de la tendencia del hombre hacia el fin o felicidad, se interesa el autor por el tema de la libertad. Y lo creemos de importancia porque nos sorprende leer en esta cuestión la afirmación siguiente: "Videtur esse dicendum quod voluntas libera sit respectu cuiuscumque voliti, sive sit finis, sive eorum quae sunt ad finem, immo magis" ${ }^{70}$. Y la verdad es que contra esta afirmación se suele reaccionar diciendo que esto es confundir la libertad con la espontaneidad. Pero la respuesta no parece ser muy convincente; y bien pudiera ser que todo dependiese de cómo se defina la libertad 71 .

a) Definición de la libertad.-Con frecuencia la libertad se entiende como un dominio de la voluntad sobre el propio acto, de tal manera que se pueda actuar

sunt enim obiecta huiusmodi termini cuiusdam relationis qua anima refertur ad res in quantum eis conformatur et assimilatur" (Fol. 85ra).

69 "Dupliciter enim dicitur aliquid moveri ab aliquo efficienter: uno modo per directam et principalem efficientiam, et hoc modo voluntas a solo Deo movetur efficienter; alio modo per quamdam conexionem et redundantiam: et hoc modo voluntas movetur ab intellectu facto in actu. Quia enim voluntas et intellectus in eadem essentia animae radicantur ideo cum anima sit in actu secundum intellectum, fit inclinatio quaedam in illa ut fiat in actu secundum voluntatem, et ut moveat secundum ipsam, et propter huiusmodi inclinationem dicitur intellectum movere voluntatem. Talis autem motio potest dici excitatio, quod etiam in aliis animae potentiis habet locum propter earum conexionem in essentia animae... et sic patet quomodo voluntas moveatur ab intellectu efficienter, scil. per modum inclinationis cuiusdam" (Fol. 85rb).

70 Fol. 83rb.

71 "Est igitur voluntas libera respectu finis si recte accipiatur ratio libertatis" (Ibid.). 
y se pueda no actuar. Pero ¿hasta qué punto esta última parte entra en la definición de la libertad? O cómo habría que entendetla si de hecho entrase? Porque la dificultad salta a la vista: Cristo nos redimió libremente, pero ¿fue libre su voluntad humana al elegir o al aceptar los medios para verificar la redención? ¿Podría haber elegido o aceptado otros, podría haber obrado de otra manera, no en abstracto sino en concreto, en las diversas circunstancias de su vida, dadas la unión hipostática, la visión beatífica y la voluntad del Padre"? Que el asunto sea difícil a nadie se le oculta. Ahí están las soluciones de los teólogos cuando de Cristo se trata, encontradas entre sí y sin que logren convencerse mutuamente. Con razón algún teólogo de nota habla de este paso de las Termópilas en teología 72 .

Pues bien, si Santiago de Viterbo insiste en que la voluntad es libre respecto de ese fin, lo hace a base de un concepto de libertad en el que nos señala antes los elementos esenciales, y creemos también que para señalarlos se fija en los datos que le proporciona la introspección de una vivencia de los actos concretos de volición, ya se trate del fin o de los medios para el fin. Según esto, lo primero que hay que tener en cuenta es que la libertad se ha de entender como perfección, no como defecto ${ }^{73}$; por consiguiente, no puede entrar el elemento necesidad, estar como atado, sometido, forzado a poner el acto ${ }^{74}$. De donde se sigue que habrá libertad para poner el acto si éste está en nuestro poder ${ }^{75}$ sin violencia por parte de un extraño, con señorío sobre el mismo. ¿Quiere esto decir que se haya de añadir necesariamente la coletilla "poder no querer o poder no poner" el acto? Expresamente nos avisa en contrario: de ninguna manera lo considera como esencial sino más bien como un indicio y señal de libertad allí donde de hecho se dé ${ }^{76}$. Por consiguiente, no se seguiría que haya libertad si en algún caso concreto no se pueda no querer ${ }^{77}$. En resumen: para una buena distinción en lo que se refiere a lo que es o no formal en la libertad nos advierte que se puede entrar a formar parte de la libertad: a) como causa eficiente de ella, Dios; b) como raíz y origen, la espiritualidad; c) como condición sin la cual no se puede hablar de

\footnotetext{
72 R. Garrigou-Lagrange, De Christo Salvatore, Torino 1945, 337.

73. "Libertas communiter accepta est immunitas a defectu, a liberando dicta, sive defectus sit in esse, scire et operari" (Ms. Ottob. Vat. lat. 196, fol. 82vb).

74 "Libertas est quaedam nobilis conditio potentiae per quam potentia non necessitatur ad actum... Quare sequitur quod illa potentia est libera quae non necessitatur ad actum" (Ibid.).

75 "Illud enim dicitur esse nobis liberum quod est in nostra potestate" (Ibid.); "Est autem voluntas libera propria libertate qua non necessitatur ad actum sed in potestate ipsius est agere" (Fol. 83rb).

76 "Licet velle et non velle sit libertatis effectus et indicium, non tamen in hoc consistit ratio libertatis" (Fol. 85vb); "Licet posse agere et non agere conveniat potentiae liberae, non tamen consistit in hoc primo ratio libertatis, sed in hoc quod est non necessitari ad actum" (Fol. 85vb).

77 "Ideoque non sequitur semper si aliquid est liber respectu alicuius quod semper hoc possit illud velle et non velle" (Fol. $85 \mathrm{vb}$ ).
} 
libertad, el entendimiento; d) como razón formal de la libertad, el no estar necesitado a poner el acto; e) finalmente, como efecto o indicio de libertad, el poder ejecutar o poder no ejecutar el acto ${ }^{78}$.

b) La libertad respecto del fin.-Visto, pues, en qué consiste la libertad, el autor se enfrenta de lleno con la cuestión del fin como objeto de la libertad. Ahora bien, en la relación voluntad-fin hay que distinguir lo que es especificativo de la voluntad y lo que es ejercicio del acto de la voluntad. Respecto de lo primero, evidentemente, hay necesidad, no libertad, al tratarse del fin, no así, según nuestro autor, cuando se trata del ejercicio ${ }^{79}$. El adversario le dirá que el no querer el fin sólo es per accidens, es decir, en aquel que no piensa en el fin ${ }^{80}$. Pero la cosa no va por ahí; no se trata de no poder no querer el fin cuando en él se piensa: esto lo admite también el autor; ya nos dijo que "no poder no querer" es un "efecto" e "indicio", cuando se da, de la libertad. Santiago de Viterbo resuelve o aclara la dificultad insistiendo en la distinción entre la voluntad como naturaleza y la voluntad en cuanto se contradistingue de aquélla. Considerada la voluntad según el primer modo, no se puede hablar de libertad respecto del fin. La tendencia a la felicidad es el "pondus" de la naturaleza intelectual, está la naturaleza necesitada, como coaccionada por el objeto; pero otra cosa sería si la voluntad se entiende como facultad distinguida contra lo naturaleza ${ }^{81}$. Dijimos antes que, sin duda

78 "Et ad maiorem evidentiam libertatis posset colligi ex iam dictis distinctio talis, videlicet quod supposita causa effectiva libertatis, quae causa Deus est, quandoque pluraliter potest aliquid ad libertatem pertinere: uno modo sicut quod est radix et origo libertatis, et hoc est esse immateriale et Deo secundum gradum naturae propinquum; secundo modo sicut illud sine quo libertas inveniri non potest, et hoc est intellectus; tertio modo sicut illud in quo formaliter consistit ratio libertatis, et hoc est non necessitari ad actum, sicut fuit ostensum; quarto modo sicut illud quod est effectus et indicium libertatis, et hoc est posse agere et non agere" (Fol. 85va-vb).

79 "Videtur enim hoc verum non esse cum voluntas tendat in finem naturaliter et ex necessitate, auod videtur libertatem excludere..." "quantum vero ad determinationem actus libera non est respectu finis sed ex necessitate movetur a fine" (Fol. 85vb). "Ad hoc autem dicitur convenienter ouod quantum ad exercitium actus voluntas libera est respectu finis" (Fol. 85vb).

80 "Sed dicet aliquis ad hoc quod quantum ad exercitium actus voluntas ex necessitate movetur respectu finis. Si enim aliquis non semper vult finem hoc est per accidens, quia non semper considerat de fine; sed dum ipsum considerat non potest ipsum non velle, et sic necessario ipsum vult. Ideoque beati semper videntes Deum non possunt non diligere ipsum. Quare absolute videtur esse dicendum quod voluntas respectu finis non est libera" (Ibid.).

81 "Quod autem dicitur moveri voluntas in finem naturaliter, si intelligatur hoc de natura secundum quod distinguitur contra voluntatem, sicut una causa distinguitur contra aliam, sic non est verum; quod enim hoc modo naturaliter movetur, necessitatur et cogitur. Si vero intelligatur secundum quod natura in voluntate includitur, in quantum voluntas participat aliquem proprium modum naturae, sic veritatem habet quod dicitur. Movetur enim hoc modo voluntas in aliquid naturaliter ut in finem ultimum quia modo naturae tendit in ipsum determinate, videlicet, et semper, nisi aliquid prohibeat; dicitur autem aliquid esse prohibens in volendo cum desunt aliqui eorum qui ad volendum requirun. tur" (Ibid.). 
juega un gran papel, en la apreciación que el autor hace respecto de la libertad de la voluntad en cuanto al fin, la introspección de la vivencia del acto concreto con que se quiere el fin. Experimentamos que, siendo la libertad una perfección de la naturaleza por una parte, y al presentar el entendimiento el fin como objeto que perfecciona a la voluntad, ésta no se siente coaccionada, ni movida violentamente, sino que produce el acto de querer el fin con pleno dominio del mismo, como sobre algo que le es muy propio y en consecuencia con su naturaleza. El no quererlo, o el poder no quererlo, sería algo así como un absurdo; algo que se opusiese formalmente al fin sería algo de suyo no elegible; luego si la voluntad no puede no querer el fin, es porque eso sería querer un imposible. Luego nada arguye contra la libertad el no poder no querer el fin; como nada arguye contra la omnipotencia divina el no poder hacer un imposible ${ }^{82}$. Es cierto que en el texto que citamos en nota se emplea la palabra sponte; creemos que la mente del autor va más allá de la simple espontaneidad al tratarse del acto voluntario respecto del fin, por la contraposición que en el mismo texto hace entre lo necesario y lo libre en el mismo acto, que ha de entenderse según lo dicho antes acerca de la voluntad como naturaleza y como facultad. Permítasenos, para terminar, citar aquí unas palabras de Muñoz Alonso que, si no hacen completamente a nuestro caso, sí a caso parecido; son éstas: "No es libre el que hace nacer de su propia individualidad la norma de su conducta, sino el que convierte en sustancia propia el deber ser de su existencia en el mundo" 83 .

\section{P. Fidel CASAdo, O. S. A.}

\footnotetext{
82 "Cum enim libertas pertineat ad perfectionem naturae quae libera dicitur, sicut posse deficere et peccare in agendo non est perfectionis sed defectus et per consequens non est libertas nec pars libertatis [sic posse non exire in actum vel posse cessare ab actu per quem agens perficiatur non est perfectionis sed imperfectionis; et per consequens absolute et simpliciter ad rationem libertatis non pertinet (Ms. Vat.)] Secundum hoc ergo dum aliquis actu de fine considerat non potest non velle finem, sed necessario ipsum vult et tamen libere tendit in ipsum quia non necessitatur ad volendum necessitate coactionis quae libertati repugnat, sed sponte movet in ipsum; dicitur autem necessario ipsum velle necessitate immovilitatis quae libertatem non tollit, quae necessitas provenit ex conditione obiecti a quo principaliter dependet perfectio potentiae" (Ibid. fol. $85 \mathrm{vb})$.
}

83' Conferencia pronunciada en 1966: "La responsabilidad de ser cristiano". 